\title{
EDITORIAL
}

\section{Getting MAD (Medical Aid in Dying) in Canada}

I am sick to death of talking about physician-assisted suicide and euthanasia. I have spent the last 25 years of my career studying palliative care; trying to unravel the complexities of issues facing dying patients and their families; and of course, attempting to devise ways and means of improving the experience for people approaching death. Our research group has examined many topics such as depression, desire for death, will to live; screening for various kinds of end-of-life distress and of course, a detailed program of studies addressing the notion of dying with dignity (Chochinov, 2002; 2006; 2012). And yet, as of late, the topic I am most often approached by the media to comment on is physician-hastened death.

Canadians are hearing a lot more about this issue lately. On June 5, 2014, the Quebec National Assembly passed what is being called An Act Respecting End-of-Life Care, the first Bill in North America legalizing euthanasia or what is euphemistically being called Medical Aid in Dying (MAD) [Bill 52, 2014]. While the Bill purports to ensure that "everyone may have access, throughout the continuum of care, to quality care that is appropriate to their needs, including prevention and relief of suffering," the only detail Bill 52 provides regarding how they will fulfill their mandate pertains to the administration and tracking of MAD. As well, the Supreme Court of Canada is currently deliberating their ruling in a case that could overturn the Criminal Code prohibition against assisted suicide.

In their zeal to cover the story about "Dying with Dignity," reporters eventually seem to stumble upon my work. That "death with dignity" has come to mean a lethal overdose or injection is surely an indictment of our healthcare system. Whether real or perceived, whether based on past experience or the absence of reassurances to the contrary, many people fear that they or their loved ones will not get the care they want and need as they approach their final days. Fear is driven by expectation and often shaped by previous experience. When one considers the limited access Canadians have to comprehensive, quality palliative care, is it any wonder people are so afraid
(Carstairs, 2002)? Watching someone die a bad death - where pain is not controlled, distress is ignored, patients and families feel abandoned, and access to home-based services is inadequate - leaves an indelible mark: a memory that turns the promise of a peaceful exit from this life into a lie. For all too many Canadians, that is, the lingering memory they carry of their loved one's death. It is a memory that will shape how they grieve and no doubt, will shape the choices they consider as they themselves approach death.

In addressing their questions, I try to tell reporters, yet again, that palliative care targeting the preservation of dignity can mitigate many of the factors that drive a patient's wish to die. Preserving dignity means providing optimal symptom management, accommodating informational, cultural and spiritual needs, paying exquisite attention to issues regarding personhood; meaning, purpose, continuity of self, role preservation, pride, acceptance and generatively. It includes attentiveness, and an ability to skillfully unravel, psychological and spiritual distress; and knowing how care tenor - a fundamental stance toward patients imbued with respect and affirmation - can profoundly shape a dying persons perspective, sense of self-worth, feelings of being a burden, and even will to live.

Reporters usually push back, reminding me of national opinion polls that indicate mounting public support for physician-hastened death. I suspect the majority of Canadians, if asked, would also support deep tax cuts and more paid vacation time. While polls are a reflection of what is popular, they do not reliably predict what makes for good social policy. And what do we make of the fact that while many people in a state of good health might see death hastening as a desirable option, only a fraction of those will avail themselves of this option in jurisdictions where it is legal? Clearly people are not very good at predicting what they might want or choose in circumstances they have not yet had to face. And what about autonomy? Surely, they beseech me as they ratchet up the pressure to engage me in this 
conversation, you would not stand in the way of autonomy? Despite waning energy, I try to explain that our autonomy is not absolute and will always be restricted based on considerations beyond our own individual needs. I will go on to say that all humans are vulnerable and that loss of ability, capacity, and autonomy - temporarily or permanently — is inevitable. When we are very young, very old, or seriously ill or injured, we can expect autonomy will be compromised. When we place autonomy in the driver's seat, any destination may be considered on course. Take for instance the former Chair of the Royal Society of Canada Panel on End-of-Life Decision-Making (Schuklenk, 2011), who found it "highly problematic" that "there is little support today, in Canada, for making assisted dying available to treatment-resistant incompetent depressed people, very young children and people who are incompetent, for instance due to mental illness" (Schuklenk, 2014). It is noteworthy that the Royal Society Panel, which concluded that the laws prohibiting physician hastened death need to be changed, did not include a single Canadian specialist in palliative care. This strikes me as akin to a Royal Society Panel on Music that fails to ask musicians to take part.

By now, if they have not already packed up their cameras or put away their note pads, reporters will be looking at me suspiciously, assuming my position must be based on an ultra-conservative, religious or morally rigid worldview. How ludicrous. There is no evidence to suggest that palliative care professionals are any more religious or morally unbending than anyone else working in healthcare. As a collective, they abhor suffering; in fact it could easily be argued that their raison d'être is to lessen suffering for people with life threatening or life limiting conditions. So why this disinclination toward death hastening? I suspect it is the same reason micro-vascular surgeons, responding to patients with crushed limbs, eschew physicians wielding saws - they understand that there are almost always better options available.

Palliative care will never eliminate all suffering, any more than medicine will eliminate death. But people working in palliative care understand the nature of suffering more so than most. They understand that suffering can be averted by providing clarity about the many choices patients have, including the ability to stop or forgo any treatments whatsoever, including those that might sustain life. They understand that suffering implicates family members and communities, and that their actions or inactions may have ripple effects impacting the soon to be bereft. They understand the complexities of a stated wish to die; the ambivalence with which such sentiments are held; the degree to which their own personal feelings of helplessness can lead to collusion with a patient's feelings of hopelessness; and how a commitment to non-abandonment is often the single most powerful, sustaining influence they can provide.

From now on, when reporters ask me to discuss physician-hastened death, I will simply send them a copy of this article. I hope they understand that no matter what the court decides, physician-hastened death will not solve the overwhelming problems facing dying patients and their families in this country - and that that is what we need to be talking about. No doubt some will find my reticence to enter into the assisted suicide/euthanasia debate, and attempts to redirect the conversation to quality palliative care, off-putting or downright annoying. That is a risk I will have to take. Hopefully, no one gets mad.

\section{ACKNOWLEDGMENT}

This article is an adaptation of a more detailed paper entitled "Is it time to Get MAD" (Healthcare Papers, 2014:14, 50-57)[http://www.longwoods.com/content/23971]).

Readers wanting to learn more about dignity conserving care are encouraged to visit dignityincare.ca.

\section{REFERENCES}

Bill 52: An Act Respecting End-of-Life. (2013). http://www. dyingwithdignity.ca/database/files/library/BILL_52 English_amendments_FINAL_with_new_numbering(1). pdf (Accessed on June 17, 2014).

Chochinov, H.M. (2006). Dying, dignity and new horizons in palliative end-of-life care. CA: Cancer Journal for Clinicians, 56, 84-103.

Chochinov, H.M. (2012). Dignity Therapy: Final Words for Final Days. Oxford: Oxford University Press.

Chochinov, H.M. (2002). Dignity conserving care: A new model for palliative care. JAMA, 287, 2253-2260.

Schuklenk, U. (2014). Assisted dying in Canada. Healthcare Papers, 14, 38-43.

Schuklenk, U. (2011). The Royal Society of Canada Expert Panel: End-of-life decision making. https://rscsrc.ca/ sites/default/files/pdf/RSCEndofLifeReport2011_EN_ Formatted_FINAL.pdf (Accessed on November 22, 2014).

The Honorable Sharon Carstairs (Chair). End-of-Life Care: The Right of Every Canadian. Standing Senate Committee on Social Affairs, Science and Technology. http:// www.parl.gc.ca/Content/SEN/Committee/362/upda/ rep/repfinjun00-e.htm (Accessed on June 17, 2014).

HARVEY MAX CHOCHINOV, M.D. Co-Editor 